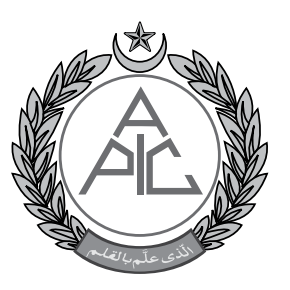

\author{
${ }^{1}$ Professor \& HOD, Department \\ of Anesthesiology \& Intensive \\ Care, Gian Sagar Medical \\ College and Hospital, Banur, \\ Patiala, Punjab, India. \\ ${ }^{2}$ Assistant Professor, \\ Department of Anesthesiology \\ and Intensive Care, Adesh \\ Medical College and Hospital, \\ Ambala, Haryana, India \\ Correspondence: \\ Professor Sukhminder Jit \\ Singh Bajwa, MD, MBA, \\ FACEE, House No-27-A, \\ Ratan Nagar, Tripuri, Patiala, \\ Punjab, India. PIN-147001, \\ Phone: +919915025828, \\ +911752352182; E-mail: \\ sukhminderbajwa@gmail.com \\ Received: 31 Oct 2018 \\ Reviewed \& Accepted: \\ 7 Nov 2018
}

\section{Overcoming barriers to implement surviving sepsis campaign guidelines}

\author{
Sukhminder Jit Singh Bajwa, MD, MBA, FACEE ${ }^{1}$, Rashi Sarna ${ }^{2}$
}

\begin{abstract}
Sepsis and systemic inflammatory response syndrome have attracted much focus during the previous few decades, as one of the most challenging cause of high mortality in patients admitted in intensive care units. Despite the availability of best of the healthcare facilities in developed countries the morbidity and mortality related to sepsis could not be eliminated. It necessitated us to divert focus on various measures to prevent sepsis. The result was a global emphasis on prevention and various strategies were suggested including 'Early Goal Directed Therapy' and Surviving Sepsis Campaign (SSC). The recommendations suggested by the Campaign may entail recruitment of additional staff and resources, so not every medical institution is very keen to implement. This editorial highlights some of the barriers to implement the guidelines presented by SSC.
\end{abstract}

Key words: Sepsis; Systemic inflammatory response syndrome; Morbidity; Mortality; Surviving Sepsis Campaign; Early Goal Directed Therapy

Citation: Bajwa SJS, Sarna R. Overcoming barriers to implement surviving sepsis campaign guidelines. Anaesth Pain \& Intensive Care 2018;22 Suppl 1:S4-S8

\section{INTRODUCTION}

Sepsis is defined as "the systemic response to infection and the presence of systemic inflammatory response syndrome (SIRS) in addition to a documented or presumed infection. Severe sepsis is sepsis with acute organ dysfunction". ${ }^{1}$ If severe sepsis is accompanied by acute circulatory failure, which is presented as persistent arterial hypotension not attributable to any other etiology, it is called septic shock. Sepsis is reported to be a leading contributor of inpatient mortality and morbidity among medical and surgical patients. ${ }^{2}$ The impact of sepsis in high income countries is reported to be between 3 and 10 per 1000 people annually. Due to lack of robust data, these figures of sepsis conundrum could possibly get unexpected inflation when data from economically weak and resource challenged nations will be audited. As per the Global Burden of Disease study, more than 10 million deaths per annum are attributable to infection globally. ${ }^{3}$ As per an estimate by Center for Disease Control and Prevention (CDC), there were about 450 thousand incident cases of sepsis in the year 1990 in United States with 100 thousand deaths. ${ }^{4}$ The overall reported incidence of sepsis is ranged between $10 \%-30 \%$ with a mortality of $10 \%$ to as high as $56 \% .^{5}$

Recognition of early symptoms of sepsis is the first step in curbing the incapacitating effects of sepsis. However, the main challenging issue in diagnosis of sepsis is the non availability of a concrete diagnostic test and over reliability on non specific biochemical markers as well as clinical parameters. The origin of sepsis also mislead the clinicians as it is difficult to identify many a times that which type of infection actually leads to sepsis.

The ill effect of sepsis gets murkier when special population at risk such as paediatric, geriatric, 
obstetric and immunocompromised patients get trapped into fatal web of sepsis. To reduce mortality and morbidity associated with sepsis, the Surviving Sepsis Campaign and the Institute for Healthcare Improvement have collaborated to incorporate a 6-h early goal directed therapy and a $24-\mathrm{h}$ management bundle into diagnosis and management of severe sepsis and septic shock. ${ }^{6-7}$

\section{Early Goal Directed Therapy (EGDT)}

In early days patients of severe sepsis and septic shock were treated in an intensive care unit (ICU), these being highly equipped and organized units in any hospital to provide specialized care to critically ill patients. ${ }^{8}$ However, Emanuel Rivers emphasized the importance of the "golden hour" lost in waiting for the transfer of patients to ICU leading to global tissue hypoxia, organ dysfunction and even death. ${ }^{9}$ Thus EGDT was proposed in the emergency department which aimed at early aggressive stabilization of the patients thus resulting in decrease in mortality rate by $16 \% .{ }^{9}$ This is an important aspect in control of sepsis as we usually do not have too many critical beds in developing countries. Moreover, the peripheral set-ups do not have well equipped centers to control the morbidity and mortality arising out of sepsis. Rather than impractically upgrading all the health care centers including peripheral health centers, emergency set-ups in all hospitals can be upgraded with minimal investment so as to timely treat the patients with life threatening emergencies and severe sepsis.

\section{Surviving Sepsis Campaign}

The Surviving Sepsis Campaign (SSC) provides recommendations to treat septic patients with an aim to decrease the morbidity and mortality associated with sepsis. ${ }^{10}$ The main recommendation of the campaign is early resuscitation of the patient, early administration of antibiotics, ICU care and continued care post admission. However, this SSC has not been able to exert its beneficial effect in uniform manner throughout globe. This editorial aims to highlight key issues and barriers in implementation of SSC especially in resource challenged nations and possible solutions to the every challenge faced by the clinician and the health administrator.

\section{Challenges and Problems: Overcoming the Barriers}

Sepsis has always remained a big challenge in low resource nations as it contributes substantially in escalating the mortality rates of in-hospital admissions. These statistics have not improved much in spite of the existing "Surviving Sepsis Campaign" guidelines. Despite the advances in intensive care therapy and availability of new-generation antibiotics having a broader spectrum of coverage, the mortality of sepsis patients remains unacceptably high. Despite continued efforts in order to improvise the treatment for sepsis, it still remains one of the leading causes of death in ICU. Multiple factors have contributed towards failure of comprehensive application and implementation of these sepsis guidelines in developing nations. Illiteracy, economic divide, lack of awareness, health inequity due to diversion of funds, poor policies of the politicians and health care delivery personals, scarce resources and various attitudinal and behavioral barriers have contributed immensely in failing to bring down the global morbidity arising from sepsis in the low resource settings.

The success against such barriers can be achieved if a concrete plan is formulated based on the various strengths and weaknesses in implementation of SSC which is possible only if a thorough evaluation and audit of various morbidity and mortality rates arising out of sepsis is done. Such measures will not only ensure the optimal utilization of health resources but will definitely improve the functioning of various health care delivery measures as well as the overall health indices of resource challenged nations. The ensuing sections will dwell upon these barriers and challenges and their possible solutions so as to successfully implement the SSC guidelines uniformly.

\section{Demographic and Environmental Factors}

It has been seen that majority of deaths due to sepsis occur more in low and middle income countries as compared to high income countries. Various factors as discussed above such as poverty, inadequate resources, poor health care systems, and many more are main contributors to the burden of sepsis in the low resource settings. Lack of awareness and illiteracy augment the poverty driven circumstances which increases the incidence of sepsis as a result of poor nutritional status, non-compliance with vaccination schedules, poor sanitation, lack of hand hygiene awareness and exposure to various other environmental hazards. ${ }^{11,12}$ To improve these conditions, it will be an herculean task and it requires initiatives from people themselves, the government and non-government agencies so as to strengthen the health care delivery system and subsystems. ${ }^{13}$

\section{Poor health care worker to patient ratio}

Health care facilities frequently lack the physician and nursing staff for standardize care for patients with sepsis. Literature shows that approximately 83 countries fail to meet the WHO standards for 
minimum health care worker-to-population ratios. ${ }^{14}$ Inadequate resources and lack of education and training of the nursing and paramedical staff is a major barrier in rapid identification and treatment of patients with sepsis. ${ }^{15} \mathrm{~A}$ poor physician to patient ratio further enhance the morbidity and mortality statistics arising out of sepsis. Studies show that bridging these knowledge gaps and meaningful staff feedback is crucial in early diagnosis and resuscitation of patients with sepsis thus improving patient outcome. Since the health setups are varied in developing nations, there should be a uniform teaching and training pattern of paramedical staff even for those who are working in the peripheral health centers. Also license should be given only to those health workers who along with teaching and training should have a minimum duration of experience in handling such patients. A 2-3 days refresher course on sepsis management should be mandatory for all these paramedical staff at least once in a year so as to renew their registration.

\section{Imbalance and shortage of health care facilities}

Many middle and low income countries lack sufficient health care facilities. Most of the health care facilities are understaffed or overcrowded, limited supply of essential medications, have poor working conditions like inadequate sanitation, ventilation, to allow for standard patient care. ${ }^{16}$ All these factors contribute towards substandard care of the patients and even contribute to the spread of hospital acquired infections. These barriers can be overcome if government appoints regional and local health administrators to look after the minimal requirements for maintaining standard care of health in each health care delivery center. It is a policy matter and involve coordination among various economic, administrative, social and political specialists especially for private sector health care.

\section{Tertiary care facilities and timely referrals}

Intensive care units are highly equipped and organized units in any hospital to provide specialized care to critically ill patients. These patients have their best shot of survival, if timely care is given. Therefore an early recognition of the severity of sepsis and the timely referral of a patient to tertiary care center is of prime importance. However, worldwide there is a relative mismatch of availability of beds in ICU and number of patients requiring them. ${ }^{17}$ Furthermore, providing ICU care incurs a huge cost in terms of financial as well as skilled professional services to the hospital. Health inequity further adds to these challenges as the affordability issues discourage the poor people from seeking timely and proper care. Further the imbalance in allocation of resources and improper prioritization of critical patient,s care can further lead to enhanced morbidity and mortality in patients suffering from sepsis. ${ }^{18}$ Some patients with sepsis may require surgical interventions in order to eliminate the source of infection. However not all health care centres are well equipped to facilitate timely surgical intervention.$^{19-20}$ In case of inadequate facilities, such patients should be referred to a higher centre preferably government center with adequate resources.

\section{Resource challenges}

The current sepsis management guidelines requires a highly -equipped and well -trained team as various procedures like intubation, ventilator settings, administration of fluids and ionotropes, blood transfusion, central venous catheter (CVC) and arterial line cannulation, ionotropic administration may need to be performed simultaneously. Many hospitals especially low income countries lack the required resources in order to effectively implement these guidelines. ${ }^{21}$ This imbalance between the recommendations and implementation of SSC guidelines mandates a modified set of guidelines based on original guidelines so as to benefit maximum number of patients in the developing nations. For such measures, creation of National Task force will be an important step as the members of such a task force can consider all the pros and cons of each guideline and then formulate their own guidelines in accordance with their resource availability (both human and material), social structure and economic scenario.

\section{Regulation of pharmacological concerns}

As already discussed health care centers in low income countries may provide limited supply of essential antimicrobials. There are hardly any stringent rules and regulations in developing nations which aims to standardize the various preparations of pharmacy industry. As a result so many inferior and substandard drugs come into the market which may be of little clinical efficacy. Such drugs increase the morbidity and mortality when used in life emergencies. Use of such medications even in not so life threatening conditions may result in an ineffective treatment of infection thus leading to poor patient outcome ${ }^{.22}$ The emerging drug resistance due to misuse or abuse of antibiotics is another challenge which needs to be addressed to decrease sepsis related morbidity and mortality. ${ }^{23-25}$ Formulation of a uniform national policy on use of antibiotics will be an important step in this regard. Further, the pharmacy industry should be functioning directly under the supervision of drug controller. Regular inspection of various drug 
manufacturing plants can help in imposition of strict rules and regulations and production of quality drugs.

\section{Rehabilitation and follow up}

Patients who survived severe sepsis may experience long term complications in the form of mental or physical disabilty. ${ }^{26}$ The functional outcome of sepsis survivors can be improved with provision of occupational, physical and speech therapy as well as psychological services. However lack of skilled nursing and re-habilitation facilities especially in low and middle income countries forms a major barrier to decreasing the burden of impairment as a result of sepsis. These health statistics can be improved to a large extent if literacy levels are good so as to create a better awareness among the general public.

The big health care delivery gap between the developed and the developing nations cannot be eliminated as long as economic gap is there. As such it will be difficult to emulate all the SSC guidelines in developing nations no matter how much good and effective they are. However, when such guidelines are formulated, representatives from developing nations should be given appropriate representation in the Task Force so that all the drawbacks and shortcomings related to the implementation of these guidelines in developing nations can be discussed at length and more resource challenged friendly guidelines can be formulated. At present, the health care gap is increasing among developed and developing nations on account of impractical approaches to forcefully impose these guidelines in all the circumstances whether suitable or not which makes it difficult to follow these guidelines. Therefore a coordination among developed and developing nations is needed at economic, social, clinical and political front so as to successfully enable the implementation of SSC guidelines in true sense.

\section{Conflict of interest: None}

Authors' contribution: Both authors took equal part in preparation of this manuscript.

\section{REFERENCES}

1. Bone RC, Balk RA, Cerra FB, Dellinger $R P$, Fein AM, Knaus WA, et al. Definitions for sepsis and organ failure and guidelines for the use of innovative therapies in sepsis. The ACCP/SCCM Consensus Conference Committee. American College of Chest Physicians/Society of Critical Care Medicine. Chest. 1992;101(6):1644-55. [PubMed] [Free full text] D0I: https:// doi.org/10.1378/chest.101.6.1644

2. Mayr FB, Yende S, Angus DC. Epidemiology of severe sepsis. Virulence. 2014;5(1):4-11.

3. Fleischmann C, Scherag A, Adhikari NK, Hartog CS, Tsaganos T, Schlattmann $P$, et al. Assessment of Global Incidence and Mortality of Hospitaltreated Sepsis. Current Estimates and Limitations. Am J Respir Crit Care Med. 2016;193(3):259-72. [PubMed] [Free full text] DOl: 10.1164/ rccm.201504-07810C

4. From the Centers for Disease Control. Increase in National Hospital Discharge Survey rates for septicemia-United States, 1979-1987. JAMA. 1990;263(7):937-8. [PubMed]

5. Alejandria M, Lansang MA, Lansang D, Ernest Fonbuena G, Fadreguilan E, Timbreza F, et al. Epidemiology and
Predictors of Mortality from Sepsis in Medical Patients at UP-PGH. Phil J Microbiol Infect Dis 2000;29(2):23-32. [Free full text]

6. Friedman G, Silva E, Vincent JL. Has the mortality of septic shock changed with time. Crit Care Med 1998;26:2078-86. [PubMed]

7. Dellinger RP, Carlet JM, Masur $\mathrm{H}$, Gerlach H, Calandra T, Cohen J, et al. Surviving sepsis campaign guidelines for management of severe sepsis and septic shock. Intensive Care Med 2004;30:536-55. [PubMed]

8. Giuliano KK, Lecardo M, Staul L. Impact of protocol watch on compliance with the surviving sepsis campaign. American Journal of Critical Care 2011;20(4):313-21. [PubMed] [Eree full text]

9. Rivers E, Nguyen B, Havstad S, Ressler J, Muzzin A, Knoblich $\mathrm{B}$, et al. Early goal-directed therapy in the treatment of severe sepsis and septic shock. N Engl J Med. 2011;345(19):1368-77. [PubMed] [Free full text] DOI: 10.1056/NEJMoa010307

10. Dellinger RP, Levy MM, Rhodes A, Annane D, Gerlach H, Opal SM, et al Surviving sepsis campaign: Inter- national guidelines for management of severe sepsis and septic shock: 2012. Crit Care Med 2013;41(2):580637. [PubMed] DOI: 10.1097/ CCM.0b013e31827e83af

11. Gavidia R, Fuentes SL, Vasquez R, Bonilla M, Ethier MC, Diorio C, et al. Low socioeconomic status is associated with prolonged times to assessment and treatment, sepsis and infectious death in pediatric fever in El Salvador. PLoS One. 2012;7(8):e43639. [PubMed] [Free full text] DOI: 10.1371/journal.pone.0043639

12. von Mollendorf C, Cohen C, de Gouveia L, Naidoo N, Meiring S, Quan V, et al. Risk factors for invasive pneumococcal disease among children less than 5 years of age in a high HIV-prevalence setting, South Africa, 2010 to 2012. Pediatr Infect Dis J. 2015;34:27-34. [PubMed] [Free full text]

13. Manongi R, Mtei F, Mtove G, Nadjm B, Muro F, Alegana V, et al. Inpatient child mortality by travel time to hospital in a rural area of Tanzania. Trop Med Int Heal. 2014;19:555-62. [PubMed] [Free full text]

14. Global Health Workforce Alliance, World Health Organization. A universal 
truth: no health without a workforce; 2013. p. 104. [PubMed] [Free full text]

15. Peltola L, Goddia C, Namboya F, Brunkhorst F, Pollach G. Sepsisknowledge of non-physician personnel in Africa: a cross-sectional study in Malawian district hospitals. Med Klin Intensivmed Notfmed. 2015;110:49 54. [PubMed] [Free full text]

16. Guo A, Bowling JM, Bartram J, Kayser G. Water, sanitation, and hygiene in rural health-care facilities: a crosssectional study in Ethiopia, Kenya, Mozambique, Rwanda, Uganda, and Zambia. Am J Trop Med Hyg. 2017;97:1033-42. [PubMed] [Free full text]

17. Murthy S, Leligdowicz A, Adhikari NK. Intensive care unit capacity in lowincome countries: a systematic review. PLoS One. 2015;10(1):e0116949. [PubMed] [Free full text]

18. Kissoon N, Burns J. Who should get pediatric intensive care when not all can? A call for international guidelines on allocation of pediatric intensive care resources. Pediatr Crit Care Med.
2014;15:82-3. [PubMed] [Free full text]

19. Alkire $B C$, Raykar NP, Shrime MG, Weiser TG, Bickler SW, Rose JA, et al. Global access to surgical care: a modelling study. Lancet Glob Heal. 2015;3: e316-23. [PubMed] [Free full text]

20. Uribe-Leitz T, Esquivel MM, Molina G, Lipsitz SR, Verguet S, Rose J, et al. Projections for achieving the lancet commission recommended surgical rate of 5000 operations per 100,000 population by region-specific surgical rate estimates. World J Surg. 2015;39:2168-72. [PubMed] [Free full text]

21. Murthy S, Leligdowicz A, Adhikari NK. Intensive care unit capacity in lowincome countries: a systematic review. PLoS One. 2015;10(1):e0116949. [PubMed] [Free full text]

22. Kelesidis T, Kelesidis I, Rafailidis PI, Falagas ME. Counterfeit or substandard antimicrobial drugs: a review of the scientific evidence. J Antimicrob Chemother. 2007;60:214-36.
[PubMed] [Free full text]

23. Ntirenganya $\mathrm{C}$, Manzi 0 , Muvunyi $\mathrm{CM}$, Ogbuagu 0 . High prevalence of antimicrobial resistance among common bacterial isolates in a tertiary healthcare facility in Rwanda. Am J Trop Med Hyg. 2015;92:865-70. [PubMed] [Free full text]

24. Bataar O, Khuderchuluun C, Lundeg G, Chimeddorj S, Brunauer A, Gradwohl-Matis I, et al. Rate and pattern of antibiotic resistance in microbiological cultures of sepsis patients in a lowmiddle-income country's ICU. Middle East J Anesthesiol. 2013;22:293300. [PubMed] [Free full text]

25. Review on Antimicrobial Resistance. Antimicrobial resistance: tackling a crisis for the health and wealth of nations. 2014. [PubMed] [Free full text]

26. Wiens MO, Pawluk S, Kissoon N, Kumbakumba E, Ansermino JM, Singer J, et al. Pediatric post-discharge mortality in resource poor countries: a systematic review. PLoS One. 2013;8(6):e66698. [PubMed] [Free full text] 